\title{
DIGNIDADE DA PESSOA HUMANA E A RESERVA DO POSSÍVEL: NAS AÇÕES DE MEDICAMENTOS
}

\author{
Igor Lins Silva ${ }^{1}$ \\ Recebido em 24/08/2020 \\ Aceito em 01/08/2021
}

\begin{abstract}
RESUMO
Este artigo analisou a relação entre o princípio da dignidade da pessoa humana e o instrumento da reserva do possível nas ações de medicamentos, tendo em vista que pela precariedade do sistema público de saúde e da escassez de recursos públicos, muitos cidadãos se utilizam de meios judiciais invocando o mínimo existencial para obter medicamentos não fornecidos pelo Estado, ocasionando um grande impacto no orçamento público. Para tal objetivo, foi feita uma análise do direito à saúde nas Constituições Brasileiras, seguido de um estudo mais aprofundado do princípio da dignidade da pessoa humana, do mínimo existencial e da reserva do possível. Foi realizada uma pesquisa jurisprudencial perante os Tribunais Superiores com o fito de buscar os julgados mais recentes sobre o tema. Aderiu-se uma metodologia com abordagem dedutiva e método de procedimento monográfico. A coleta de dados utilizada foi a de documentação indireta, por meio de livros e jurisprudências dos tribunais superiores. Concluiu-se que enquanto não houver maior diálogo entre os Poderes, o mínimo existencial e a reserva do possível sempre serão utilizados como um meio de tentar mascarar os diversos problemas de gestão do Poder Público.
\end{abstract}

Palavras-chave: Reserva do possível; Dignidade da pessoa humana; Medicamentos; Saúde; Estado.

\section{DIGNITY OF THE HUMAN PERSON AND THE RESERVE OF POSSIBLE: IN}

\section{DRUG LAWSUITS}

\section{ABSTRACT}

This article analyze the relationship between the principle of the dignity of the human person and the instrument of reserving the possible in the drug lawsuits, bearing in mind that due to the precariousness of the public health system and the scarcity of public resources, many citizens use judicial means invoking the minimum existencial to obtain medicines not supplied by the State, causing a great impact on the public budget. For this purpose, an analysis of the right to health in the Brazilian Constitutions was made, followed by a more in-depth study of the principle of human dignity, the minimum existential and the reserve of the possible. A jurisprudence survey from the Superior Courts in order to seek the most recent judgments on the subject. A methodology with a deductive approach and a monographic procedure method was used. The data collection used was indirect documentation, through books and jurisprudence from the Superior Courts. It was concluded that as long as there is no dialogue between the Powers, the minimum existencial and the reserve of the possible will always be used as a means of

\footnotetext{
${ }^{1}$ Discente de Direito do Centro Universitário de Educação Superior do Estado do Amazonas - CIESA. E-mail: igorlinsbelarmino@gmail.com
} 
trying to mask the various management problems of the Public Power.

Keywords: Reserve of possible; Dignity of the human person; Drugs; Public health system; State.

\section{INTRODUÇÃO}

Este artigo busca abordar, de forma crítica, o conflito que a sociedade atual vivencia entre a dignidade da pessoa humana e o direito à reserva do possível nas ações de medicamentos.

Não obstante, diante da escassez e da má utilização dos recursos públicos, o Poder Judiciário tem formulado políticas públicas que se concretiza por meio de suas decisões e jurisprudências que impõe ao Poder Executivo o atendimento a pretensão daqueles que buscam o Estado para garantir o direito à saúde. Esta decisão visa fornecer aos litigantes os medicamentos necessários à saúde, no entanto, não há consulta para averiguar se o Ente Público possui recursos suficientes para efetivar a medida judicial.

Ademais, o Sistema Único de Saúde - SUS, não possui capacidade para atender todos os seus usuários, o que resulta em seus beneficiários ajuizarem ações perante o Judiciário para buscarem, principalmente, medicamentos de alto custo e não fornecidos pelo SUS.

Mesmo se tratando de direito fundamental previsto no artigo 196, da Carta Magna de 1988, o direito à saúde, como todo direito, não é absoluto, devendo sempre observar a possibilidade financeira e a viabilidade da Administração Pública em fornecer o medicamento.

Conforme abordado neste artigo, como forma de amenizar o choque entre a reserva do possível e do mínimo existencial, os Tribunais Superiores têm buscado ao longo dos anos uma maneira de conciliar a necessidade do impetrante em obter os medicamentos para a garantia do direito fundamental e a viabilidade orçamentária do Ente Público em fornecê-lo.

Para conseguir analisar o tema, temos inicialmente a abordagem do Direito à saúde como um direito fundamental garantido nas Constituições Brasileiras, desde 1824 até os dias atuais, com a Constituição que foi denominada de "cidadã", o que nos leva a compreender a importância desse direito. Em seguida analisamos o principio da dignidade da pessoa humana, que deve estar presente nas políticas públicas de qualquer Estado democrático de Direito, como forma de respeito ao ser humano e de garantir uma existência digna. A medida de fornecimento de medicamentos é então estudado, como forma de garantir o direito fundamental à saúde, buscando entender especialmente, em análise final, a reserva do possível como limite na implementação dos direitos sociais. 


\section{O DIREITO À SAÚDE NAS CONSTITUIÇÕES BRASILEIRAS}

O direito à saúde teve sua primeira aparição no ordenamento jurídico brasileiro na Constituição de 1824, previsto no artigo 179, inciso XXXI, sob o nome de "'socorros públicos". Todavia, conforme informa Silva (2013, p. 77-78) os direitos garantidos na Constituição de 1824 eram dirigidos à elite aristocrática que dominava o regime, "'não se pretendia reformar a estrutura colonial de produção, não se tratava de mudar a estrutura da sociedade: tanto é assim que em todos os movimentos revolucionários se procurou garantir a propriedade escrava'.

Com a Constituição de 1891 houve clara regressão na eficácia social, visto que não foram previstos, como na Constituição anterior, o direito ao socorro público e nem à instrução pública gratuita (SILVA, 2013). Portanto, a conquista ao direito à saúde que se iniciava na história do Direito no Brasil, voltava a ser negligenciado pelo Estado apesar dos reclames sociais.

Ademais, a história do Direito avança com a Constituição de 1934, que em seu art. 138, alínea ' $f$ ', incumbiu à União, os Estados e os Municípios de adotar medidas legislativas e administrativas tendentes a combater a mortalidade e a infância. Novamente os direitos sociais ganhavam espaço no cenário político e jurídico do Estado democrático de Direito no Brasil.

Após avanços e retrocessos, somente na atual Constituição, promulgada em 1988, que recebeu o título de Constituição "cidadã", em especial em seu artigo $6^{\text {a }}$, houve uma maior preocupação com os direitos sociais do povo brasileiro.

\section{$[\ldots]$}

Art. $6^{\circ}$. São direitos sociais a educação, a saúde, a alimentação, o trabalho, a moradia, o transporte, o lazer, a segurança, a previdência social, a proteção à maternidade e à infância, a assistência aos desamparados, na forma desta Constituição (grifou-se).

Portanto, a Constituição Federal de 1988 foi a primeira a consagrar o direito fundamental à saúde, segundo Mendes e Branco (2017, p. 695), visto que as Constituições anteriores somente possuíam disposições rasas do tema, sem efetividade que garantisse, em especial, o fornecimento dos medicamentos necessários à saúde dos cidadãos que buscam tratamento adequado para todos os tipos de doenças, o que garante uma vida digna para todos, conforme o princípio universal da dignidade humana. 


\section{O DIREITO À DIGNIDADE HUMANA}

Primeiramente, para falar sobre dignidade da pessoa humana, é necessário adentrar no ramo filosófico. Sarlet (1998, p. 212) dizia que "a dignidade é expressão da posição social ocupada pelo individuo e pelo grau de reconhecimento que os demais componentes daquela comunidade atribuíam a um sujeito". Logo, para o filósofo, existiriam pessoas mais ou menos dignas socialmente. A dignidade não era atributo do cidadão, mas direito de membros da sociedade que gozavam de posição social diferenciada.

Essa definição sofreria grandes mudanças ao longo do tempo, pois o filósofo alemão Immanuel Kant, no iluminismo alemão, começou a defender a autonomia moral do indivíduo. Para Kant (1980) 'o homem deve ser levado a sério, sendo sempre o fim maior das relações humanas e nunca o meio"'.

Corroborando a ideia Kantiana, de que o homem deve ser o centro das relações humanas, Gonçalves (2020, p. 347) afirma que pela teoria constitucional majoritária, a dignidade da pessoa humana, regulada pelo art. $1^{\circ}, \mathrm{III}$, da $\mathrm{CR} / 88$, é erigida à condição de meta-princípio, ou seja, irradia valores e vetores de interpretação para os demais direitos fundamentais. Esta tese é aceita pela corrente majoritária, como alicerce para a garantia da dignidade do ser humano defendida pela atual Constituição.

Outro importante jurista, ministro do Supremo Tribunal Federal, Luís Roberto Barroso, afirmou que:

\footnotetext{
[...] para finalidades jurídicas, a dignidade da pessoa humana pode ser dividida em três componentes: valor intrínseco, o qual se refere ao status especial do ser humano e como indivíduo livre e igual, tomar decisões e perseguir o seu próprio ideal de vida boa; autonomia, que expressa o direito de tomar decisões e perseguir o seu próprio ideal de vida boa; e valor comunitário, convencionalmente definido como a interferência estatal legítima na determinação dos limites da autonomia pessoal (BARROSO, 2012, p. 112).
}

Neste diapasão percebemos que os parâmetros mínimos para aferir a consecução normativa do supracitado princípio, visa a garantia da dignidade humana em bases sólidas de acordo com políticas públicas que aliem a efetivação jurídica e a administração do Estado. Tais parâmetros foram elencados por Fernandes (2020, p. 351):

- Não Instrumentalização, que busca proteger a essência do ser humano, buscando impedir que ele seja instrumentalizado, ou seja, não pode se tratado como meio para obtenção de determinado fim; 
- Autonomia existencial, a qual determina que todas as pessoas devem ter o direito de fazer suas escolhas essenciais de vida e agir de acordo com suas escolhas desde que elas não sejam práticas ilícitas;

- O Direito ao Mínimo Existencial, o qual determina que existam condições básicas para uma vida digna;

- Direito ao Reconhecimento, o qual expõe a ideia de que as injustiças podem se dar não apenas no campo da redistribuição de bens, mas também no campo do reconhecimento, portanto, é necessário respeitar as identidades singulares.

Este cenário alia as esferas do Poder Público à sociedade no reconhecimento do princípio da dignidade da vida humana e abre espaço para o debate acerca do direito à saúde como direito fundamental, cuja efetividade somente é possível a partir do fornecimento de medicamentos que possam garantir o tratamento ou cura dos pacientes que necessitam da atenção do Estado.

\section{DO DIREITO À SAÚDE E O FRONECIMENTO DE MEDICAMENTOS}

Tendo em vista que o Direito ao mínimo existencial determina condições básicas para uma vida digna, todo cidadão tem o direito fundamental ao mínimo que garanta sua vida digna. Diante disso, Silva (2013, p. 309) afirma ser indiscutível que o direito à saúde relaciona-se de forma direta com o direito à vida.

Primeiramente, é de suma importância estabelecer o conceito de saúde, estabelecido no artigo 196 da Constituição Federal de 1988:

Art. 196. A saúde é direito de todos e dever do Estado, garantido mediante políticas sociais e econômicas que visem à redução do risco de doença e de outros agravos e ao acesso universal e igualitário às ações e serviços para sua promoção, proteção e recuperação. (grifou-se).

Para garantir esse direito, muitos precisam recorrer às "ações de saúde", que são de relevância pública, conforme estabelece o art. 197 da Carta Magna de 1988, cabendo ao Poder Público dispor, nos termos da lei, "sobre sua regulamentação, fiscalização e controle, devendo sua execução ser feita diretamente ou através de terceiros e, também, por pessoa física ou jurídica de direito privado".

Segundo Reissigner (2008, p. 105), há dois modelos de medidas de saúde: as medidas de saúde preventiva e as medidas de saúde curativa. O primeiro se revelaria como um status de 
liberdade positiva, conectado ao mínimo existencial. O Segundo se apresenta como um status positivo social.

Neste entendimento, podemos encontrar na doutrina majoritária dois aspectos relacionados aos direitos sociais. Estas duas vertentes abordam o direito à saúde de forma peculiar. De acordo com Pedro Lenza, a existência da natureza negativa determina que o Estado ou particular devem abster-se de praticar atos que prejudiquem terceiros, já a existência de natureza positiva estabelece uma posição de fomento por parte do Estado prestacionista para implementar o direito social (LENZA, 2018, p. 1339).

Como forma de reforçar a natureza obrigacional por parte do Estado nas ações de saúde, a Emenda Constitucional n 29\% $/ 00$, o $§ 2$ do art. 198 passou a dispor da obrigatoriedade de uma aplicação de recursos mínimos em ações e serviços públicos de saúde, transformando essa reserva de recursos como norma de observância obrigatória, inclusive sob pena de intervenção no caso de descumprimento, conforme determina o art. 34, VII, '"e' da CF/88.

O Sistema único de saúde é a garantia do direito à saúde para muitos cidadãos que não têm renda para arcar com altos custos do tratamento para a garantia da saúde ou mesmo da vida. Como leciona Menezes:

[...] hoje há dois sistemas de saúde no País: o SUS, gratuito, por vezes precário, mas com acesso universal, que a própria prática reservou para as famílias de baixa renda; e o sistema privado contributivo e, em tese, de boa qualidade, seletivamente reservado às classes economicamente superiores (MENEZES, 2015, p. 126).

E ainda segue a análise desse distanciamento social crescente no Brasil, onde as reais necessidades de saúde da população brasileira de baixa renda poderiam ser solucionados com políticas públicas efetivas de saúde com baixo impacto financeiro por parte do Estado, conforme a citação abaixo:

Cerca de $80 \%$ dos problemas de saúde da população brasileira seriam passíveis de serem resolvidos pelo atendimento de primeira linha (rede básica de serviços de saúde: centros de saúde, ambulatórios etc.); no entanto, criou-se no Pais, uma infraestrutura de serviços altamente complexa, com alta densidade tecnológica, sem integração e hierarquização dos serviços, de acordo com sua complexidade tecnológica. Como resultado, a população passa a ser atendida por serviços cuja lógica de acesso não responde à relação disponibilidade de atendimento, mas à necessidade de lucratividade do setor privado. (COHN E ELIAS, 1996, p 117, apud MENEZES, 2015, p 126)

O Sistema Público de Saúde - SUS é regulamentado pela lei 8.080/90, e segundo Menezes (2015. p. 127) cabe ao Setor Público a adoção de medidas de caráter coletivo como vacinação em massa, controle de moléstias transmissíveis, etc. Porém, nos últimos anos, houve um crescente atendimento de caráter individual. 
Nesse sentido podemos entender que o SUS é responsável por oferecer à população em geral as mais diversas especialidades médicas, desde o procedimento mais simples aos mais complexos. Porém, o sistema não se comunica bem com a sociedade sobre qual serviço está prestando e para quem, e não supri todas as necessidades dos usuários (MENEZES, 2015. p. 134).

Perante este cenário de não suprir todas as necessidades dos usuários, o Superior Tribunal de Justiça decidiu pela possibilidade de concessão judicial de medicamentos não previstos pelo SUS, conforme decidido no Edcl no REsp 1657156/RJ, Relatória do Ministro Benedito Gonçalves, na $1^{\circ}$ Seção, vejamos:

PROCESSUAL CIVIL. ART. 494, I, DO CPC/2015. CORREÇ̃̃O DE INEXATIDÃO MATERIAL. ALTERAÇÃO DO TERMO INICIAL DA MODULAÇÃO DOS EFEITOS DO REPETITIVO.

1. O inciso I do art. 494 do CPC/2015 possibilita ao julgador a correção de ofício de eventuais inexatidões materiais no decisum. 2. No caso dos autos, a fim de evitar dúvidas, impõe-se a alteração do termo inicial da modulação dos efeitos. 3. Ante o exposto, de ofício, altera-se o termo inicial da modulação dos efeitos, do presente recurso especial repetitivo, para a data da publicação do acórdão embargado (4/5/2018).

TESE FIXADA: A tese fixada no julgamento repetitivo passa a ser: A concessão dos medicamentos não incorporados em atos normativos do SUS exige a presença cumulativa dos seguintes requisitos: i) Comprovação, por meio de laudo médico fundamentado e circunstanciado expedido por médico que assiste o paciente, da imprescindibilidade ou necessidade do medicamento, assim como da ineficácia, para o tratamento da moléstia, dos fármacos fornecidos pelo SUS; ii) incapacidade financeira de arcar com o custo do medicamento prescrito; iii) existência de registro do medicamento na ANVISA, observados os usos autorizados pela agência. Modula-se os efeitos do presente repetitivo de forma que os requisitos acima elencados sejam exigidos de forma cumulativa somente quanto aos processos distribuídos a partir da data da publicação do acórdão embargado, ou seja, 4/5/2018. (EDcl no REsp 1657156/RJ, Rel. Ministro BENEDITO GONÇALVES, PRIMEIRA SEÇÃO, julgado em 12/09/2018, DJe 21/09/2018).

Em apartada síntese do julgado acima, para o fornecimento de medicamentos não previstos pelo SUS, é necessário o preenchimento de 03 (três) requisitos essenciais:

I) comprovação, por meio de laudo médico fundamentado e circunstanciado expedido por médico que assiste o paciente, da imprescindibilidade ou necessidade do medicamento, assim como da ineficácia, para o tratamento da moléstia, dos fármacos fornecidos pelo SUS;

II) incapacidade financeira de arcar com o custo do medicamento prescrito;

III) existência de registro do medicamento na ANVISA, observados os usos autorizados pela agência.

Outra via de efetivação do direito à saúde se dá pela ação do Ministério Público, que, através da ação civil pública, tem legitimidade para provocar o Poder Judiciário quanto às omissões totais ou parciais por parte do Poder Público na implementação das ações e serviços 
de saúde, conforme fora cristalizado tanto pelo Superior Tribunal de Justiça, quanto pelo Supremo Tribunal Federal:

O Ministério Público é parte legítima para ajuizamento de ação civil pública que vise o fornecimento de remédios a portadores de certa doença. STF. Plenário. RE 605533/MG, Rel. Min. Marco Aurélio, julgado em 15/8/2018 (repercussão geral) (Info 911).

O Ministério Público é parte legítima para pleitear tratamento médico ou entrega de medicamentos nas demandas de saúde propostas contra os entes federativos, mesmo quando se tratar de feitos contendo beneficiários individualizados, porque se refere a direitos individuais indisponíveis, na forma do art. $1^{o}$ da Lei n. 8.625/1993 (Lei Orgânica Nacional do Ministério Público).

STJ. $1^{a}$ Seção. REsp 1682836-SP, Rel. Min. Og Fernandes, julgado em 25/04/2018 (recurso repetitivo) (Info 624).

Ademais, já foi pacificado a possibilidade de fornecimento, pelo entendimento do Poder Judiciário, de medicamentos não registrados pela Agência Nacional de Vigilância Sanitária ANVISA, conforme a jurisprudência do Supremo Tribunal Federal. Vejamos:

\begin{abstract}
Ementa: CONSTITUCIONAL E ADMINISTRATIVO. EMBARGOS DE DECLARAÇÃO EM RECURSO EXTRAORDINÁRIO COM REPERCUSSÃO GERAL RECONHECIDA. AUSÊNCIA DE OMISSÃO, CONTRADIÇÃO OU OBSCURIDADE. DESENVOLVIMENTO DO PROCEDENTE. POSSIBILIDADE. RESPONSABILIDADE DE SOLIDÁRIA NAS DEMANDAS PRESTACIONAIS NA ÁREA DA SAÚDE. DESPROVIMENTO DOS EMBARGOS DE DECLARAÇÃO. 1. É da jurisprudência do Supremo Tribunal Federal que o tratamento médico adequado aos necessitados se insere no rol dos deveres do Estado, porquanto responsabilidade solidária dos entes federados. $O$ polo passivo pode ser composto por qualquer um deles, isoladamente ou conjuntamente. 2. A fim de otimizar a compensação entre os entes federados, compete à autoridade judicial, diante dos critérios constitucionais de descentralização e hierarquização, direcionar, caso a caso, o cumprimento conforme as regras de repartição de competências e determinar o ressarcimento a quem suportou o ônus financeiro. 3. As ações que demandem fornecimento de medicamentos sem registro na ANVISA deverão necessariamente ser propostas em face da União. Precedente específico: RE 657.718, Rel. Min. Alexandre de Moraes. 4. Embargos de declaração desprovidos.
\end{abstract}

(RE 855178 ED, Relator(a): Min. LUIZ FUX, Relator(a) p/ Acórdão: Min. EDSON FACHIN, Tribunal Pleno, julgado em 23/05/2019, PROCESSO ELETRÔNICO DJe090 DIVULG 15-04-2020 PUBLIC 16-04-2020).

Ato contínuo, conforme Cavalcante (2019), em estudo realizado do julgado acima, é possível o fornecimento de medicamentos fora do rol da ANVISA quando preenchidos os seguintes requisitos:

Fornecimento pelo Poder Judiciário de medicamentos não registrados pela ANVISA 1. O Estado não pode ser obrigado a fornecer medicamentos experimentais. 2. A ausência de registro na Agência Nacional de Vigilância Sanitária (Anvisa) impede, como regra geral, o fornecimento de medicamento por decisão judicial.

3. É possível, excepcionalmente, a concessão judicial de medicamento sem registro

Ponto de Vista Jurídico | Caçador | v.10 |nº 1 | p. 24 - 33 |jan./jun. 2021 
sanitário, em caso de mora irrazoável da Anvisa em apreciar o pedido (prazo superior ao previsto na Lei 13.411/2016), quando preenchidos três requisitos:

a) a existência de pedido de registro do medicamento no Brasil (salvo no caso de medicamentos órfãos para doenças raras e ultrarraras);

b) a existência de registro do medicamento em renomadas agências de regulação no exterior;

c) a inexistência de substituto terapêutico com registro no Brasil.

4. As ações que demandem fornecimento de medicamentos sem registro na Anvisa deverão necessariamente ser propostas em face da União.

STF. Plenário. RE 657718/MG, rel. orig. Min. Marco Aurélio, red. p/ o ac. Min. Roberto Barroso, julgado em 22/5/2019 (repercussão geral) (Info 941).

\section{REFERÊNCIAS}

BARROSO, Luís Roberto. A dignidade da pessoa humana no direito constitucional contemporâneo: a construção de um conceito jurídico da jurisprudência, p. 112, 2012.

BRASIL. Superior Tribunal de Justiça. Recurso Especial $n^{\circ}$ 1185474/SC - Santa Catarina. Relator: Ministro Humberto Martins. Disponível em:<https://stj.jusbrasil.com.br/jurisprudencia/9119367/recurso-especial-resp-1185474-sc2010-0048628-4/inteiro-teor-14265399>. Acesso em: 15/07/2020.

BRASIL. Supremo Tribunal Federal. ADPF n ${ }^{\circ}$ 45/DF - Distrito Federal. Relator: Ministro Celso de Mello. Disponível em <https://stf.jusbrasil.com.br/jurisprudencia/14800508/medidacautelar-em-arguicao-de-descumprimento-de-preceito-fundamental-adpf-45-df-stf $>$. Acesso em: $15 / 07 / 2020$.

BRASIL. Constituição (1988). Constituição da República Federativa do Brasil. Brasília, DF: Senado Federal: Centro Gráfico, 1988.

CAVALCANTE, Márcio André Lopes. Fornecimento pelo Poder Judiciário de medicamentos não registrados pela ANVISA. Buscador Dizer o Direito, Manaus. Disponível em:

<https://www.buscadordizerodireito.com.br/jurisprudencia/detalhes/4d7a968bb636e25818ff2 a3941db08c1>. Acesso em: 13/07/2020.

CAVALCANTE, Márcio André Lopes. Legitimidade do MP para ajuizar ação pedindo o fornecimento de medicamento. Buscador Dizer o Direito, Manaus. Disponível em: $<$ https://www.buscadordizerodireito.com.br/jurisprudencia/detalhes/05f17e3cfa5de42020eaa6 df34fb4805>. Acesso em: 13/07/2020.

CAVAlCANTE, Márcio André Lopes. Requisitos para a concessão judicial de medicamentos não previstos pelo SUS. Buscador Dizer o Direito, Manaus. Disponível em: $<$ https://www.buscadordizerodireito.com.br/jurisprudencia/detalhes/27b09e189a405b6cca 6ddd7ec869c143>. Acesso em: 13/07/2020.

FERNANDES, Bernardo Gonçalves, Curso de Direito Constitucional. $12^{\mathrm{a}}$ ed. Atualizada e ampliada. Editora JusPodivm, 2020.

KANT, Immanuel. Fundamentação da metafísica dos costumes. Trad. Paulo Quintela. 2 ed. 
São Paulo: Abril Cultural, 1980. [Os Pensadores]

LEITE, Harrison; Manual de Direito Financeiro. $8^{\text {a }}$ ed. Editora JusPodivm. 2019.

LENZA, Pedro. Direito Constitucional Esquematizado. 22 a ed. São Paulo: Saraiva, p 1339, 2018.

MENDES, Gilmar Ferreira; BRANCO, Paulo Gustavo Gonet. Curso de direito constitucional. 12a ed. São Paulo: Saraiva, pg. 695-697 2017.

MENEZES, Victor Hugo Mota de, Direto à Saúde e Reserva do Possível. Curitiba Juruá, 2015.

REISSINGER, Simone. Aspectos controvertidos do direito à saúde na constituição brasileira de 1988. 2008. Dissertação (Mestrado em Direito Público) - Faculdade Mineira de Direito, Pontifícia Universidade Católica de Minas Gerais, Belo Horizonte, 2008.

SARLET, Ingo Wolfgang. A eficácia dos direitos fundamentais. Porto Alegre: Livraria do Advogado, 1998.

SARMENTO, Daniel, Por um Constitucionalismo Inclusivo, Editora: Lumen Juris; Edição $1^{\text {a }}, 1$ de janeiro de 2010, p 199-201

SILVA, José Afonso da. Curso de Direito Constitucional Positivo. 36ed. Ver. E atual. São Paulo: Malheiros, 2013 